ISSN: 1858-4837; E-ISSN: 2598-019X

Volume 16, Nomor 2 (2021),

https://jurnal.uns.ac.id/region

DOI: $10.20961 /$ region.v16i2.31692

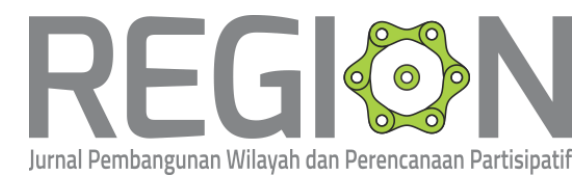

\title{
Integrasi creative hub terhadap kawasan historis Tunjungan di Kota Surabaya
}

\author{
The integration of creative hub with the historical area of Tunjungan in \\ Surabaya City
}

\author{
N Hidayat ${ }^{1}$, R Nugroho $^{1}$, dan 0 Purwani ${ }^{1}$ \\ ${ }^{1}$ Program Studi Arsitektur, Fakultas Teknik, Universitas Sebelas Maret
}

Corresponding author's email: nasrulx@outlook.com

\begin{abstract}
Abstrak. Tunjungan diyakini sebagai suatu fragmen kota yang dinamis. Identitasnya akan tetap sama sebagai sebuah artefak urban yang dapat berperan sebagai penanda zaman. Namun, faktor yang mengidentifikasinya dapat berbeda tergantung pada aktivitas yang mengisi ruang-ruang pada struktur kawasan. Kini, Tunjungan mengalami fenomena lost space. Sehingga, Tunjungan perlu untuk diklaim ulang sebagai sebuah kawasan yang akan tetap menandai perkembangan aktivitas masyarakat Kota Surabaya. Tujuan dari studi ini adalah untuk mereartikulasi identitas Tunjungan dengan menggunakan fenomena ekonomi kreatif sebagai pop-culture yang sedang tumbuh di Indonesia. Masyarakat kota akan difamiliarkan mengenai proses kreatif dengan cara menginjeksikan kegiatan kreatif sebagai aktivitas baru yang akan mengaktivasi Kawasan Historis Tunjungan. Proses injeksi kegiatan kreatif pada struktur kawasan akan dimanifestasikan dalam tipologi arsitektur berupa sebuah hub atau pusat kegiatan kreatif melalui penempatan program-program arsitektur yang disisipkan pada titik tertentu dan mengintegrasikannya dengan konteks saat ini. Program-program yang akan menunjang hub berupa maker dan creative space, serta akan direncanakan berintegrasi dengan Kawasan Historis Tunjungan dan koridor coworking space sebagai ruang kreatif eksisting yang dikelola oleh Pemerintah Kota Surabaya. Hasil dari studi ini merupakan sebuah creative hub yang terintegrasi dengan Kawasan Historis Tunjungan yang dispekulasikan dapat berperan sebagai katalisator pertumbuhan kawasan dan dipercayai secara generik dapat mereartikulasikan identitas Tunjungan sebagai distrik kreatif.
\end{abstract}

Kata Kunci: Creative Hub; Integrasi; Kawasan Historis Tunjungan; Urban Katalis

Received: July 04, 2019; Accepted: August 10, 2019; Available online: July 15, 2021

Copyright $\odot$ 2021, REGION: Jurnal Pembangunan Wilayah dan Perencanaan Partisipatif 


\begin{abstract}
Tunjungan is believed to be a dynamic city fragment. Its identity will remain the same as an urban artifact as the sign of times. However, the identifying factors can differ depending on the activities that occupy the spaces in the structure of the area. Now, Tunjungan experiences the phenomenon of lost space. Therefore, Tunjungan needs to be reclaimed as an area that will continue to mark the activities of the people of Surabaya. The purpose of this study is to rearticulate Tunjungan's identity by using the phenomenon of creative economy as a pop-culture which currently growing in Indonesia. City communities will be familiarized with the creative process by introducing the creative activities as new activities that will activate the Tunjungan Historical Area. The process of introducing creative activities into the structure of the area will be manifested in architectural typology in the form of a hub through the architectural programs which are inserted at a certain point and integrate them with the current context. The programs to support the hub are maker and creative space. Those programs are going to be planned then integrated with the co-working space corridor as the existing creative space in Tunjungan Historical Area managed by Surabaya City Government. The result of this study is a creative hub integrated with Tunjungan Historical Area which is expected to be a catalyst for regional growth and is believed as generic to re-articulate Tunjungan's identity as a creative district.
\end{abstract}

Keywords: Creative Hub; Integration; Tunjungan Historical Area; Urban Catalyst

\title{
1. Pendahuluan
}

Tunjungan merupakan salah satu jalan protokol di Kota Surabaya yang kehadirannya merupakan hasil dari proses panjang dari perubahan sistem agraria menjadi industri yang dimulai sejak abad ke-19 [1]. Sejak saat itu, Kawasan Historis Tunjungan dapat diidentifikasi sebagai salah satu area yang menjadi penanda perkembangan Kota Surabaya. Perkembangannya hingga kini dapat dibagi menjadi beberapa pembabakan [2]. Perkembangan yang tumbuh paling signifikan terjadi pada saat disebutnya Kawasan Historis Tunjungan sebagai New European Garden Sub-Urban. Menurut Faber dalam Dick [3], Kawasan Tunjungan merupakan salah satu manifestasi dari dunia Eropa yang lebih hidup, percaya diri, dan mandiri dari tahun-tahun antar perang sebagai pusat perbelanjaan dan rekreasi kota. 


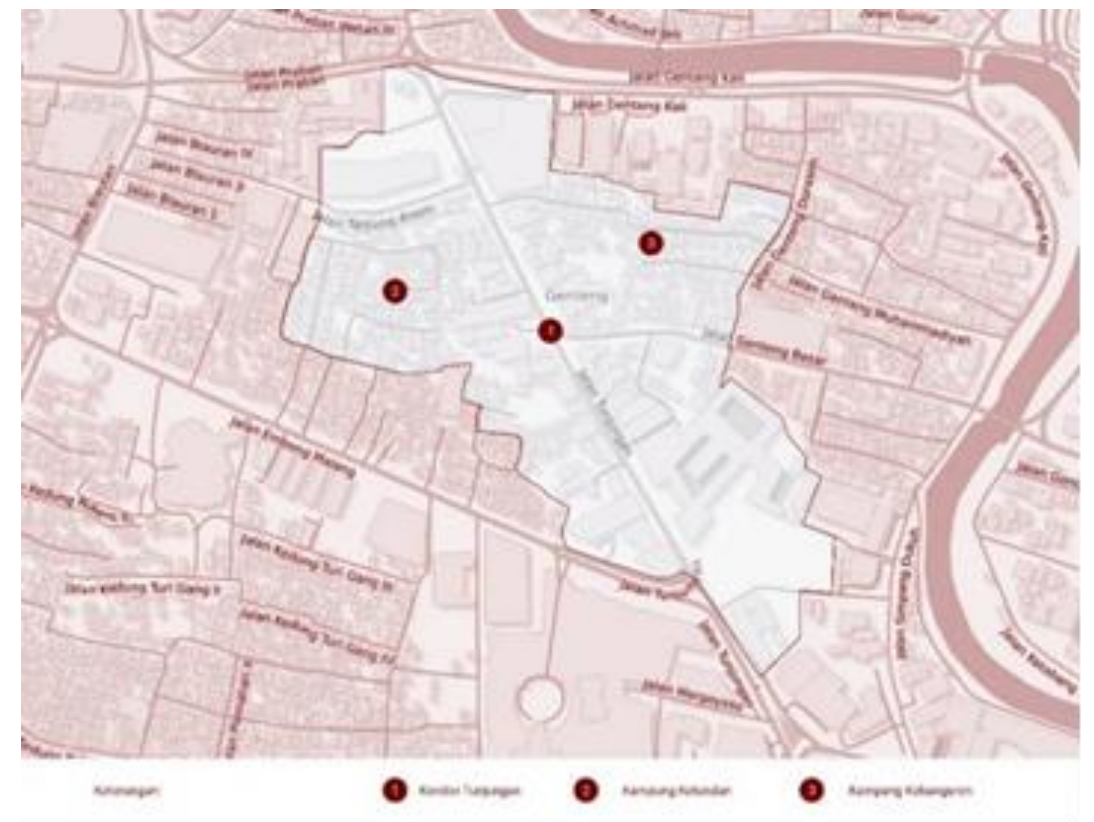

Gambar 1. Struktur kawasan tunjungan.

Kawasan Historis Tunjungan (lihat Gambar 1) merupakan kawasan dengan struktur yang terdiri dari, Koridor Jalan Tunjungan, Kampung Ketandan, dan Kampung Genteng. Secara administratif, Tunjungan termasuk dalam wilayah Kelurahan Genteng, Kecamatan Genteng, Kota Surabaya.

Tunjungan diyakini sebagai suatu fragmen kota yang dinamis. Identitasnya akan tetap sama sebagai sebuah artefak urban yang dapat berperan sebagai penanda zaman (lihat Gambar 2). Namun, hal-hal yang mengidentifikasinya dapat berbeda tergantung pada aktivitas yang mengisi ruang-ruang pada struktur Kawasan Historis Tunjungan. Banyak hal yang telah terjadi pada proses panjang perubahannya, ia pernah tumbuh dengan identitas sebagai New European Garden Suburban, berkembang dan stagnan, hingga kini hilang sebagai lost space [4].

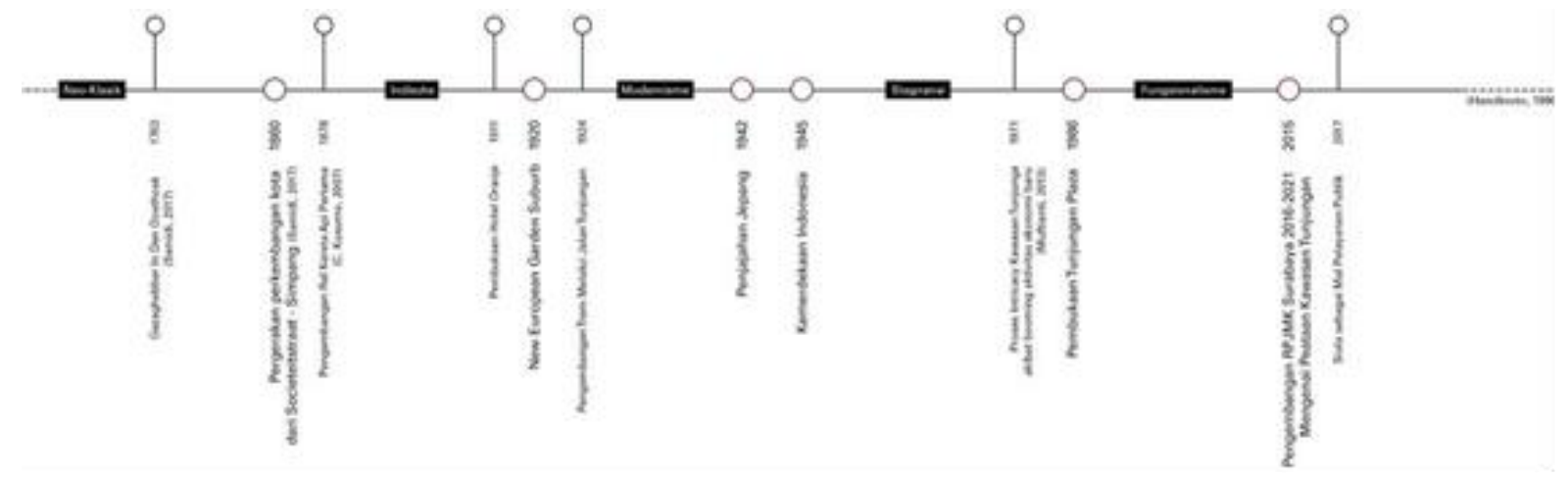

Gambar 2. Skema perkembangan kawasan $[1,2,5,6]$.

Stagnansi ini dilihat sebagai sebuah isu yang menarik manakala kawasan sebagai fragmen kota yang dinamis, mulai ditinggalkan oleh masyarakat kota sebagai lost space. Padahal, Kawasan 
Historis Tunjungan dapat dijustifikasi sebagai salah satu pembentuk identitas dan citra Kota Surabaya. Lost space dapat didefinisikan sebagai suatu area pada sebuah kota yang membutuhkan redesain karena telah menjadi ruang yang tidak memiliki kontribusi positif terhadap sekelilingnya [7].

Oleh karena itu, Tunjungan perlu untuk diklaim ulang sebagai sebuah kawasan yang akan tetap menandai perkembangan aktivitas masyarakat Kota Surabaya. Proses reartikulasi identitas Tunjungan akan menggunakan fenomena pop-culture, yakni kegiatan pada lingkup ekonomi kreatif. Masyarakat kota akan difamiliarkan dengan cara menginjeksikan kegiatan kreatif sebagai aktivitas baru yang akan mengaktivasi kembali Kawasan Historis Tunjungan.

Ekonomi kreatif pertama kali dikenalkan oleh John Howkins [8] dalam bukunya yang berjudul The Creative Economy: How People Make Money form Ideas. Terminologi ini kemudian menjadi sebuah konsep baru dalam sektor ekonomi yang dilakukan untuk memberikan penambahan nilai terhadap suatu barang dan jasa dengan pendekatan yang berbasis pada kreativitas. Di Indonesia, konsep ekonomi kreatif mulai berkembang dan memberikan dampak pada sekitar tahun 1996 hingga 2000 [9]. Perkembangan konsep ini dapat diidentifikasi melalui aktivasi ruang-ruang dengan basis kegiatan kreatif. Lahirnya ruang-ruang kreatif ini awalnya digunakan oleh sekelompok masyarakat urban untuk menunjukkan sebuah upaya independensi dalam penyediaan alternatif ide, ruang, dan pendekatan dalam membangun sebuah komunitas. Saat ini, perkembangan ruang-ruang kreatif tidak lagi terbatas pada upaya independensi pembentukan komunitas, namun telah menjadi bagian dari sebuah budaya urban ketika lahirnya ruang-ruang ini berasal dari area residual.

Perkembangan konsep ekonomi kreatif dengan aktivasi ruang-ruang kreatif pada saat ini dapat ditandai dengan kemunculan creative hub sebagai sebuah tipologi arsitektur yang juga dapat berperan sebagai sebuah distrik maupun jaringan dengan fungsi untuk mewadahi proses kreatif [10]. Pewadahan proses kreatif inilah yang kemudian diwujudkan melalui salah satu dan/atau keseluruhan program-program arsitektur, yakni creative, co-working, dan maker space [9].

\section{Metode}

Kerangka berpikir yang digunakan pada proses desain secara keseluruhan menggunakan pendekatan rasionalistik guna untuk merumuskan argumentasi logis berdasarkan fakta-fakta yang ada di lapangan. Proses perumusan argumentasi ini menggunakan metode force-based desain [11], yang digunakan sebagai alat dalam melakukan proses analisis dan sintesis dengan menggunakan domain pengetahuan lain di luar arsitektur, yakni proses kreatif.

Proses kreatif dieksplorasi menggunakan tahapan dalam proses berpikir kreatif yang dirumuskan melalui hierarki proses berpikir kreatif menggunakan versi Bloom [12]. Proses berpikir ini menghasilkan skema identifikasi konteks yang ditunjukkan dalam Gambar 3. 


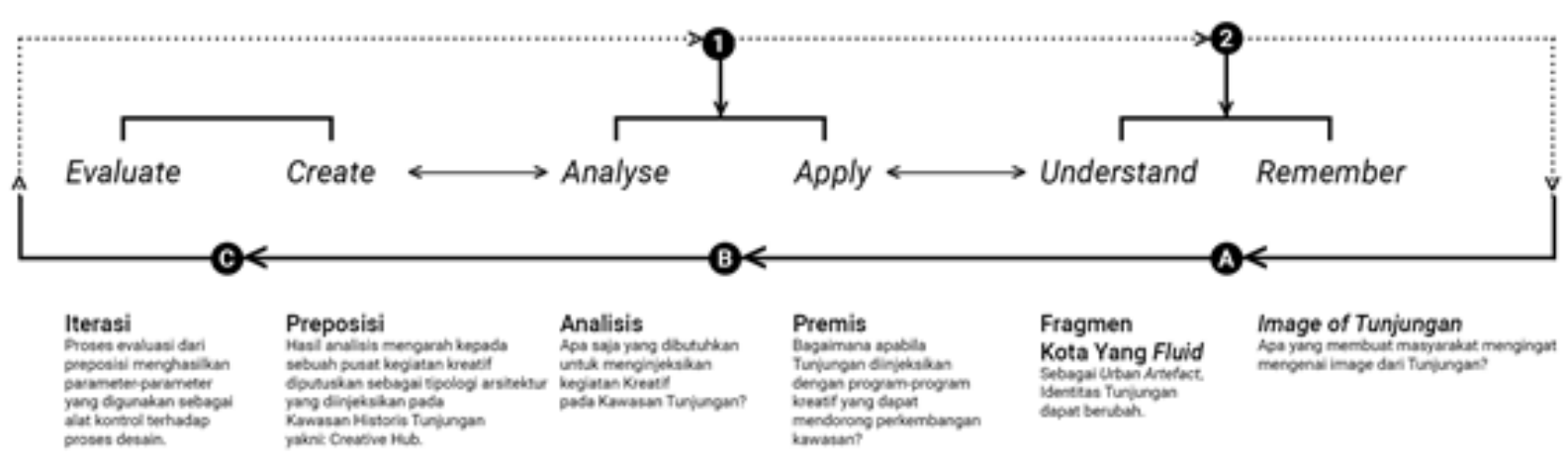

Gambar 3. Skema identifikasi konteks [12].

Aplikasi konsep kegiatan kreatif ini dapat memunculkan premis mengenai kegiatan kreatif sebagai pop-culture masa kini dapat mengaktivasi kawasan dengan cara menginjeksikan program-program arsitektur yang didapatkan dari implementasi kegiatan kreatif.

Hasil eksplorasi mengenai proses kreatif yang menghasilkan program-program arsitektur dikembalikan pada konteks Tunjungan saat ini sebagai artefak urban yang menjadi pembentuk identitas Kota Surabaya melalui aktivitas yang mengisi ruang-ruang dalam struktur kawasan. Argumentasi ini kemudian membentuk hipotesis desain, yakni untuk mengatasi stagnansi perkembangan Kawasan Historis Tunjungan, dapat digunakan program-program baru untuk diinjeksikan sebagai pewadahan aktivitas yang berbeda dari perencanaan awal Tunjungan. Proses injeksi memiliki tujuan yang sama dengan revitalisasi, yakni untuk melakukan perbaikan pada aspek fisik, ekonomi, dan sosial [13]. Namun, injeksi dilakukan hanya dengan menyisipkan beberapa program pada titik tertentu.

Proses injeksi kegiatan kreatif pada struktur kawasan akan dimanifestasikan dalam tipologi arsitektur berupa sebuah hub atau pusat kegiatan dengan kegiatan kreatif sebagai aktivitas yang diwadahi. Manifestasi hub dipercayai sebagai sebuah cara untuk mengaktivasi kawasan melalui penempatan program-program arsitektur yang berlainan dengan perencanaan awal Tunjungan dan mengintegrasikannya dengan konteks saat ini sehingga dapat memberikan kesempatan kepada masyarakat kota untuk berjejaring, berbagi pengetahuan, dan bereksperimen dalam lingkup kegiatan kreatif.

Kegiatan kreatif diyakini sebagai suatu cara yang dapat menjadi katalis pada konteks kawasan. Dari kata kunci kreatif dilakukan eksplorasi untuk mencari tahu mengenai bagaimana kreativititas pada diri manusia dapat terbentuk [14] hingga menghasilkan persyaratanpersyaratan ruang yang memberikan stimulus kreatif menurut proposisi dari penelitian mengenai klasifikasi dan parameter keberhasilan sebuah ruang kreatif [15].

Secara paralel, kata kunci integrasi akan dieksplorasi untuk mengintegrasikan programprogram dalam bentuk tipologi creative hub pada konteks kawasan. Eksplorasi ini menghasilkan tentang bagaimana spatial cognition [16] berpengaruh terhadap cara manusia memahami transperceptual space. Pemahaman ini kemudian diyakini dapat mendorong seseorang atau sekelompok manusia untuk merasakan fragmen-fragmen di kawasan yang 
merupakan bagian dari sejarah yang telah lalu dan bagian-bagian baru yang turut memberikan proses identifikasi baru bagi Kawasan Historis Tunjungan [17].

\section{Hasil penelitian dan pembahasan}

Creative hub diputuskan sebagai tipologi arsitektur yang akan diinjeksikan dalam konteks Kawasan Historis Tunjungan dan diharapkan sebagai katalis dengan tujuan untuk memicu perkembangan kawasan. Creative hub akan dibagi menjadi tiga kelompok program utama, yakni creative, co-working, dan maker space. Pembagian tiga kelompok program ini didasarkan pada hasil pemetaan British Council mengenai jenis-jenis creative hub yang telah ada di Indonesia [9]. Penginjeksian ruang-ruang kreatif ini akan disebar melalui penempatan pada beberapa area yang diinformasikan melalui Gambar 4.

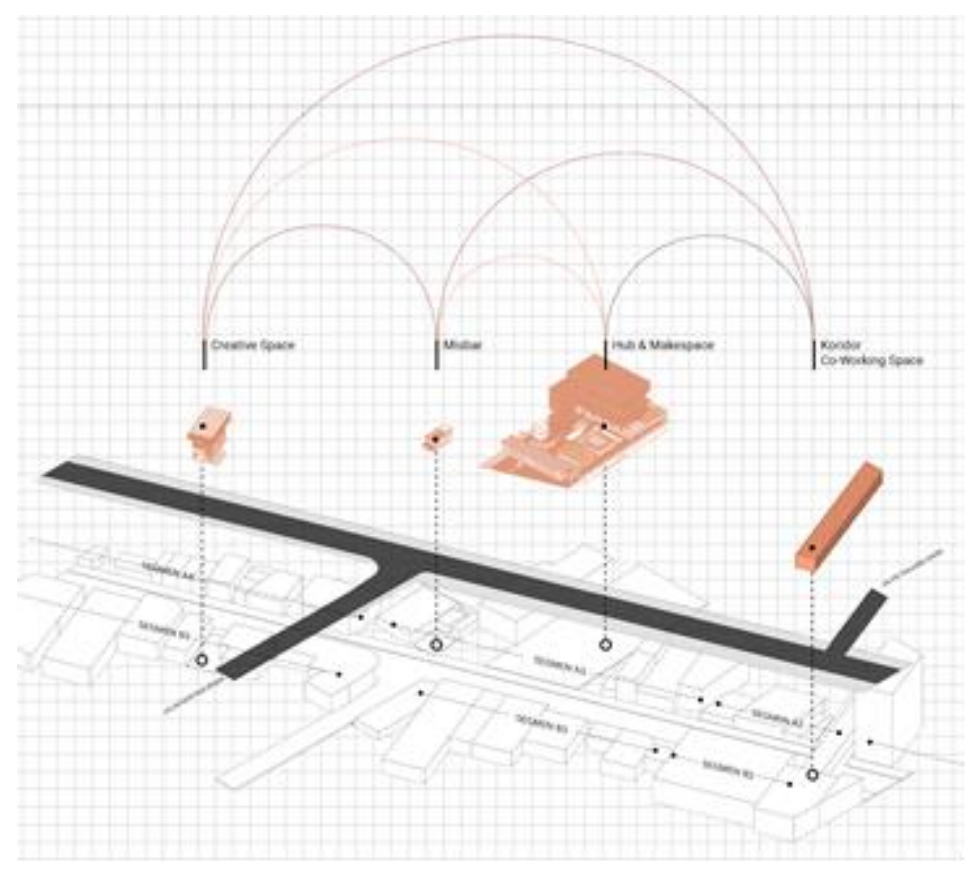

Gambar 4. Diagram hubungan antar-program.

Setiap kelompok program yang akan diinjeksikan pada kawasan memiliki fungsinya masingmasing. Creative space memiliki fungsi untuk mewadahi proses pertukaran pengetahuan dan informasi dari setiap individu maupun kelompok. Creative space memiliki program derivatif, yakni misbar sebagai amfiteater khusus untuk memberikan pertukaran pengetahuan dalam bentuk film dan videografi.

Maker space memiliki fungsi untuk mewadahi proses making dengan inisiatif dari setiap individu. Program-program pada maker space akan digabung bersama hub sebagai forum dan pusat kegiatan kreatif pada kawasan. Sedangkan co-working space merupakan ruang kreatif eksisting yang telah dikembangkan oleh Pemerintah Kota Surabaya dan pada studi ini akan diintegrasikan dengan ketiga kelompok program utama, yaitu hub, creative dan maker space untuk membentuk sebuah distrik kreatif yang ditunjukkan pada Gambar 5. 


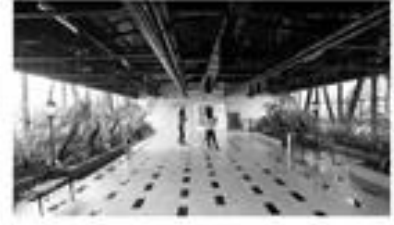

Korisor Co-working Space

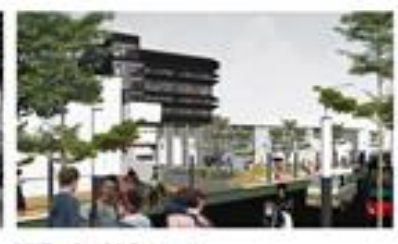

Huet dan Makerspace

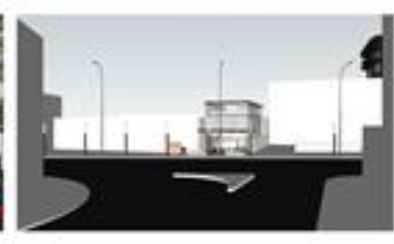

Misbar Tunjungan

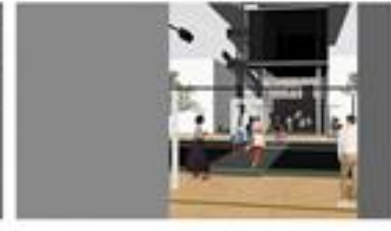

Creative Space

Gambar 5. Jenis program utama.

\subsection{Aplikasi ruang kreatif}

Ketiga kelompok program utama yang akan diinjeksikan akan dibagi dalam lima karakteristik, sehingga menjadi program derivatif yang memiliki kriteria sebagai ruang kreatif [15]. Adapun ruang-ruang ini adalah personal, collaboration, making, presentation, dan transition space yang diilustrasikan pada Gambar 6.

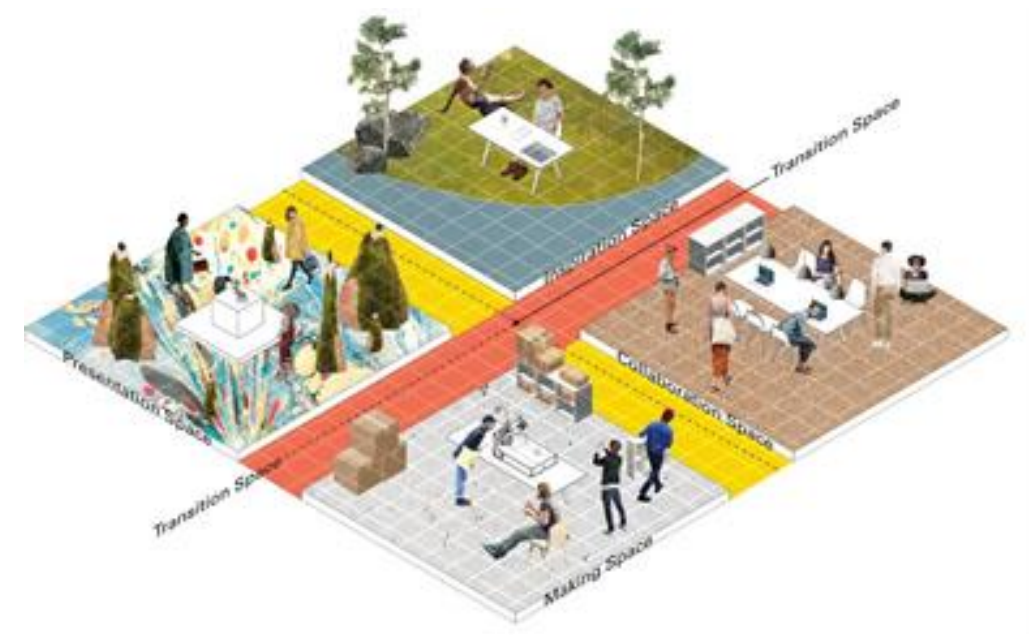

Gambar 6. Karakteristik ruang kreatif [15].

Pada dasarnya, aplikasi ruang kreatif digunakan sebagai sarana untuk memudahkan pertukaran pengetahuan pada proses kreatif, antara lain: pengetahuan eksplisit, impisit, dan tacit. Pengetahuan implisit didapatkan melalui pemahaman yang menggunakan metode dan belum tersaji secara utuh [18], hasil dari pemahaman pengetahuan implisit dapat berupa pengetahuan eksplisit. Sedangkan pengetahuan tacit merupakan jenis pengetahuan praktikal [19]. Pengetahuan-pengetahuan dalam proses kreatif ini didapatkan melalui high order thinking skill [20]. Kelima jenis ruang kreatif akan dijelaskan sebagai berikut ini.

3.1.1 Personal space. Personal space memiliki fungsi untuk memberikan ruang yang mewadahi aktivasi pengetahuan implisit melalui high order thinking skill [20]. Perpustakaan (lihat Gambar 7) dan ruang riset akan diimplementasikan sebagai personal space dengan fungsi sebagai ruang yang memberikan akses dalam perwujudan ide dan gagasan. Program ini akan diletakkan pada area yang memiliki stimulus suara dengan intensitas minimum untuk mengoptimalisasi proses high order thinking skill setiap pengguna. Optimalisasi proses berpikir kreatif ini bertujuan untuk menggali proses pengetahuan implisit untuk kemudian ditransfer dalam bentuk pengetahuan eksplisit. 


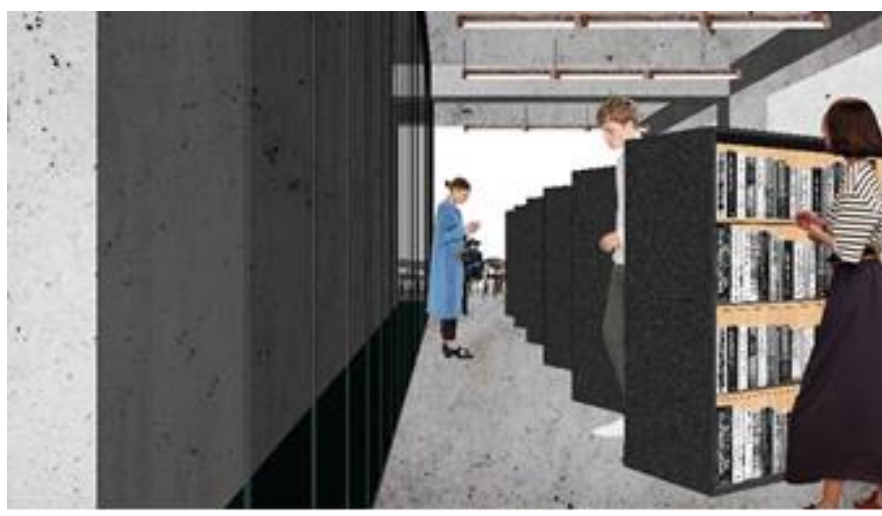

Gambar 7. Perpustakaan sebagai personal space.

3.1.2 Collaboration space. Collaboration space menjadi ruang yang memicu interaksi sosial untuk mengoptimalisasi proses sharing-knowledge [15]. Proses kolaborasi akan diwadahi oleh ruang-ruang kubikel sehingga dapat memicu interaksi sosial yang dapat mengoptimalisasi proses pertukaran pengetahuan berbentuk implisit. Untuk mengoptimalisasi proses pertukaran pengetahuan antar pengguna, kubikel akan direncanakan sebagai program dengan fungsi yang fleksibel. Fleksibilitas program ini kemudian dapat memudahkan proses berkolaborasi antar pengguna sesuai dengan kebutuhan masing-masing dengan skema penggunaan ruang yang akan diatur oleh pengelola hub. Berikut ilustrasi dari kubikel yang dapat dilihat pada Gambar 8.

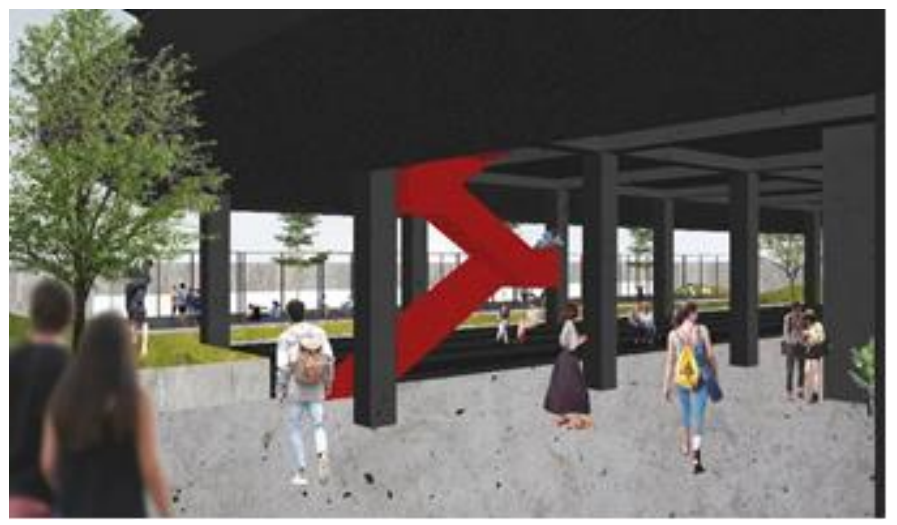

Gambar 8. Kubikel sebagai collaboration space.

3.1.3 Maker space. Proses making akan diwadahi oleh program utama, yakni maker space dengan aplikasi ruang, seperti inkubasi start-up, digital dan game development, woodworking, serta metalworking workshop. Making space (lihat Gambar 9) akan mengoptimalisasi perkembangan kreativitas little-c pada pengguna tersegmentasi [21] dengan cara memberikan kesempatan kepada pengguna untuk melakukan kegiatan berbasis do it yourself [22]. 


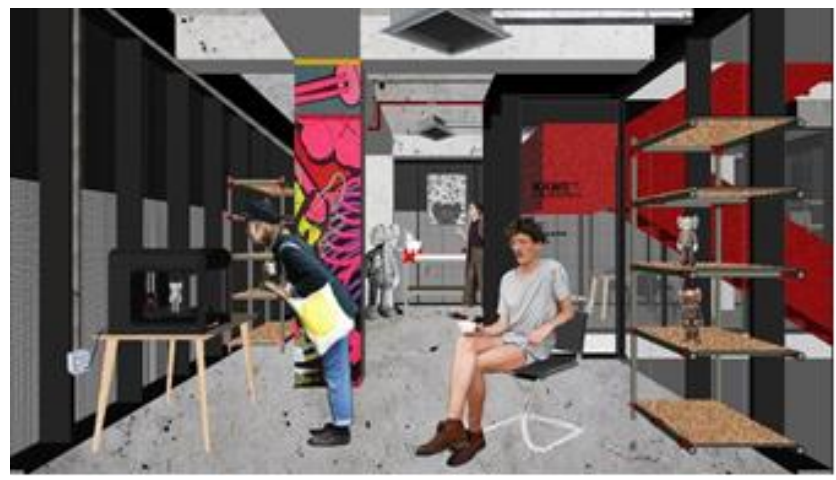

Gambar 9. Modul maker space sebagai perwadahan proses making.

3.1.4 Presentation space. Aplikasi presentation space dalam bentuk program ruang adalah ruang pamer pada hub, Tunjungan Creative Space, dan misbar. Hasil dari proses making yang telah dilakukan oleh pengguna akan dipamerkan melalui presentation space. Proses pameran ini akan menjadi kunci untuk proses familiarisasi pengetahuan kreatif dalam bentuk pertukaran pengetahuan secara eksplisit kepada masyarakat umum. Proses pertukaran pengetahuan yang terjadi pada presentation space dapat diterjemahkan dalam beberapa bentuk, yakni dari proses menunjukkan karya hingga diskusi hasil karya.

Ruang pamer pada hub (lihat Gambar 10) akan diposisikan sebagai program yang akan menjembatani antara hub dan maker space dengan Kawasan Tunjungan. Sebelum pengguna masuk lebih dalam pada kelompok program untuk melakukan proses kreatif yang membutuhkan high order thinking skill, pengguna akan dipengaruhi terlebih dahulu oleh karya-karya yang telah dihasilkan sebagai proses pertukaran pengetahuan secara eksplisit.

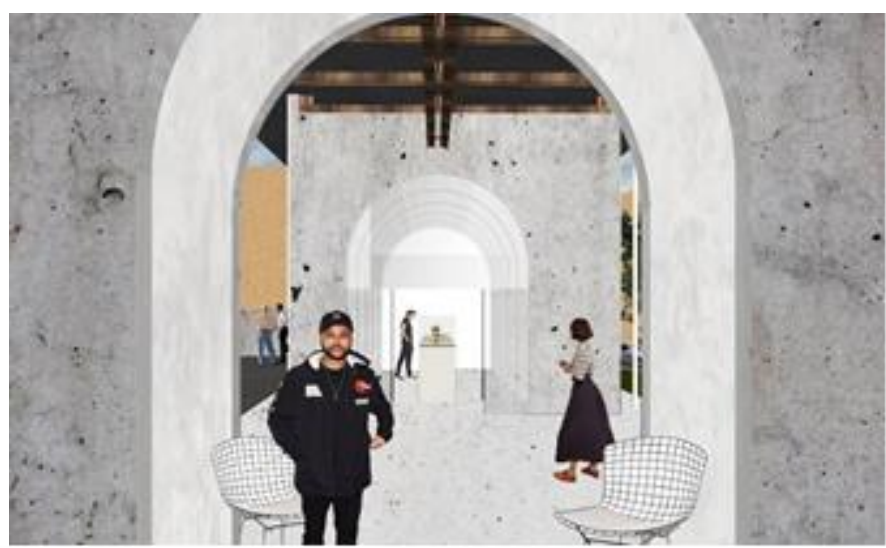

Gambar 10. Ruang pamer pada hub.

Tunjungan Creative Space sebagai ruang-ruang pamer memberikan kesempatan kepada komunitas kreatif lokal untuk menunjukkan hasil karyanya kepada khalayak yang lebih luas. Ilustrasi mengenai creative space sebagai ruang-ruang pamer tersebut dapat dilihat pada 
Gambar 11. Proses pertukaran informasi dan pengetahuan secara eksplisit akan direkayasa sedemikian rupa sehingga masyarakat yang hadir dapat menerima pengetahuan serta dapat merasakan bahwa kegiatan kreatif memang benar-benar hadir pada Kawasan Tunjungan.

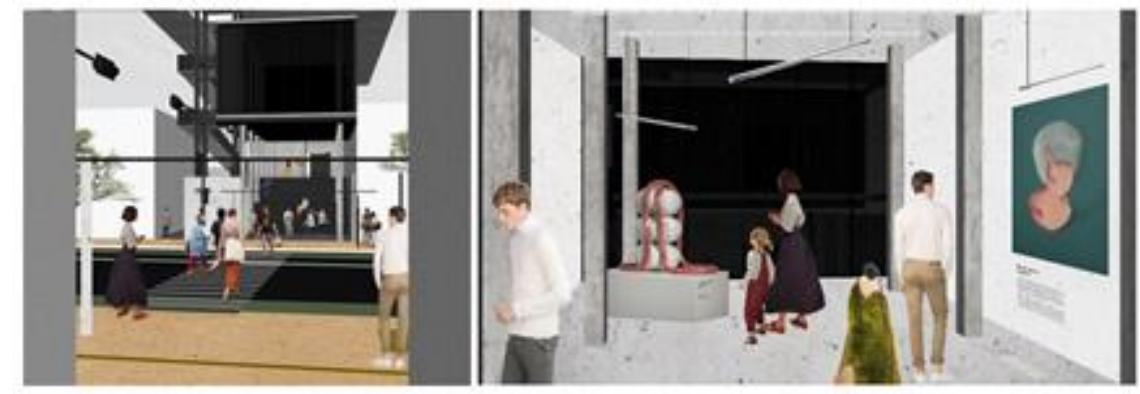

Gambar 11. Creative space sebagai presentation spaces utama.

Nama misbar mengadopsi dari frasa 'gerimis bubar', sebuah fenomena layar tancap yang sudah dialami oleh masyarakat Indonesia sebelum adanya perkembangan televisi. Dengan sistem yang sama, HUB+ akan mengimplementasikan fenomena misbar dalam konteks Kawasan Historis Tunjungan sebagai program yang mengakomodasi proses diseminasi hasil proses penciptaan film dan sinematografi oleh komunitas kreatif di Surabaya dalam bentuk amfiteater terbuka yang dapat dilihat ilustrasinya pada Gambar 12. Kegiatan lain yang mungkin akan diwadahi adalah diskusi yang dilakukan oleh individu maupun kelompok yang akan berbagi pengetahuannya dalam bentuk eksplisit.

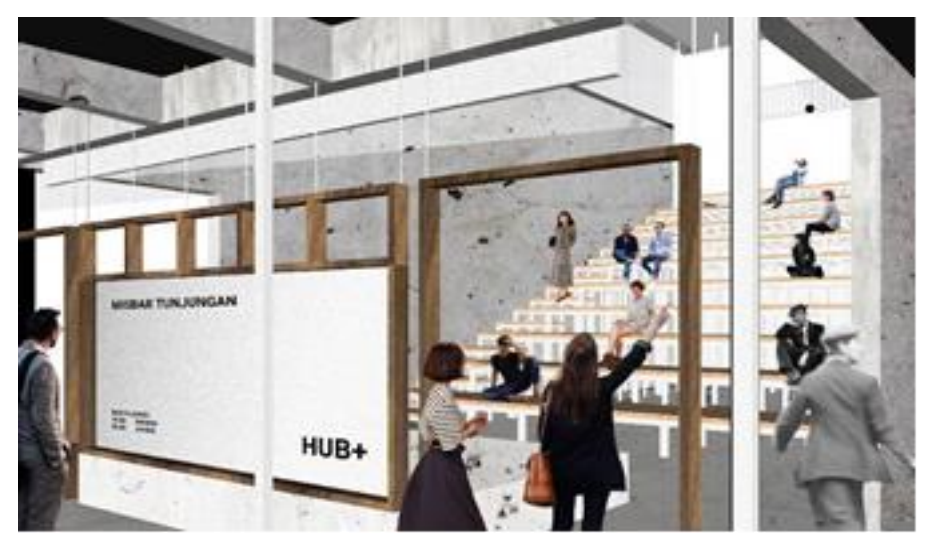

Gambar 12. Misbar sebagai presentation space digital.

3.1.5 Transition space. Ruang tansisi akan difungsikan sebagai jeda terhadap setiap proses kreatif sehingga dapat memberikan kesempatan meruang, merenung, dan berdialog pada setiap pengguna (lihat Gambar 13). Program-program yang direncanakan terhubung melalui sequence perjalanan dari satu titik program ke program yang lain untuk membantu dalam menjembatani proses pemahaman informasi dan pengetahuan yang didapatkan oleh setiap pengguna. 


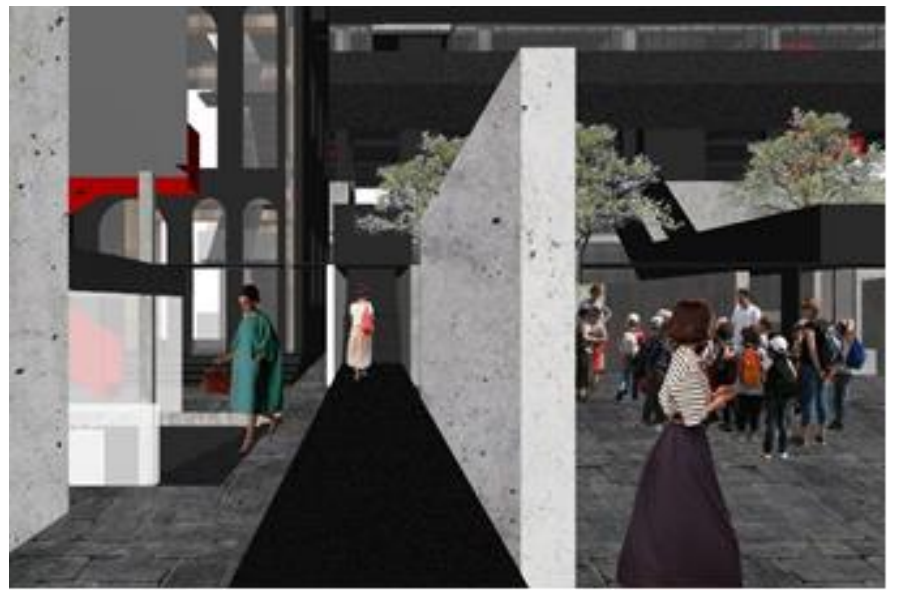

Gambar 13. Aplikasi sequence perjalanan.

\subsection{Integrasi}

Integrasi dapat digunakan sebagai sebuah cara untuk memenuhi kesempatan masyarakat Kota Surabaya untuk memposisikan Kawasan Tunjungan sebagai museum perkembangan kota [17]. Tunjungan sebagai museum perkembangan kota dapat dicapai dengan cara memberikan kebebasan kepada setiap zaman untuk mengekspresikan identitas arsitekturnya masingmasing karena apabila dirunut pada timeline perkembangan kawasan, terdapat banyak langgam arsitektur yang mengisi Tunjungan. Hal ini akan mengaktivasi sistem kognisi spasial manusia [16] untuk mengidentifikasi komponen-komponen baru dan lama tanpa memposisikan keduanya sebagai bagian yang berbeda. Sehingga, proses unifikasi dari program-program injeksi dengan Kawasan Tunjungan dapat dimaknai sebagai satu kesatuan utuh sebagai identitas Tunjungan yang baru berupa distrik kreatif.

Selain itu, integrasi juga dapat digunakan untuk menghubungkan program-program yang telah diinjeksikan terhadap kawasan menggunakan sebuah sistem dan infrastruktur yang fungsional sehingga dapat dicapai sebuah kesatuan antara komponen-komponen baru (dalam kasus ini adalah program-program yang akan diinjeksikan) dengan komponen lama untuk menghindari segregasi sosial [23]. Sejalan dengan pendapat yang dikemukakan oleh [24], dimana kota merupakan sebuah hasil dari pencampuran antara bentuk - yang merepresentasikan sebuah media penyimpanan dari bangunan-bangunan yang secara spasial terhubung dalam sebuah sistem dan infrastruktur - dan fungsi - yang mendukung serangkaian operasi dari faktor-faktor sosial, ekonomi, budaya, dan lingkungan.

Implementasi infrastruktur yang fungsional diwujudkan berupa jalur pedestrian sebagai ruang publik yang menjadi transistor antar program-program yang diinjeksikan dengan Kawasan Tunjungan. Hal ini juga didukung dengan fakta berupa kondisi jalur pedestrian Kawasan Historis Tunjungan yang masih perlu untuk dikembangkan dalam beberapa aspek, seperti penambahan street amenities dan pembagian area pada jalur pedestrian, terkait dengan respon terhadap aktivitas pedestrian [25]. 
Kualitas dari jalur pedestrian dapat ditentukan dari kemudahan perpindahan pengguna dari satu titik program ke program yang lain. Variabel-variabel yang menjadi penanda kenyamanan jalur pedestrian adalah dimensi yang mencukupi aktivitas perpidahan manusia dan ketersediaan fasilitas penyebrangan, peneduh, pelindung, serta street furniture [26] yang diilustrasikan pada Gambar 14.

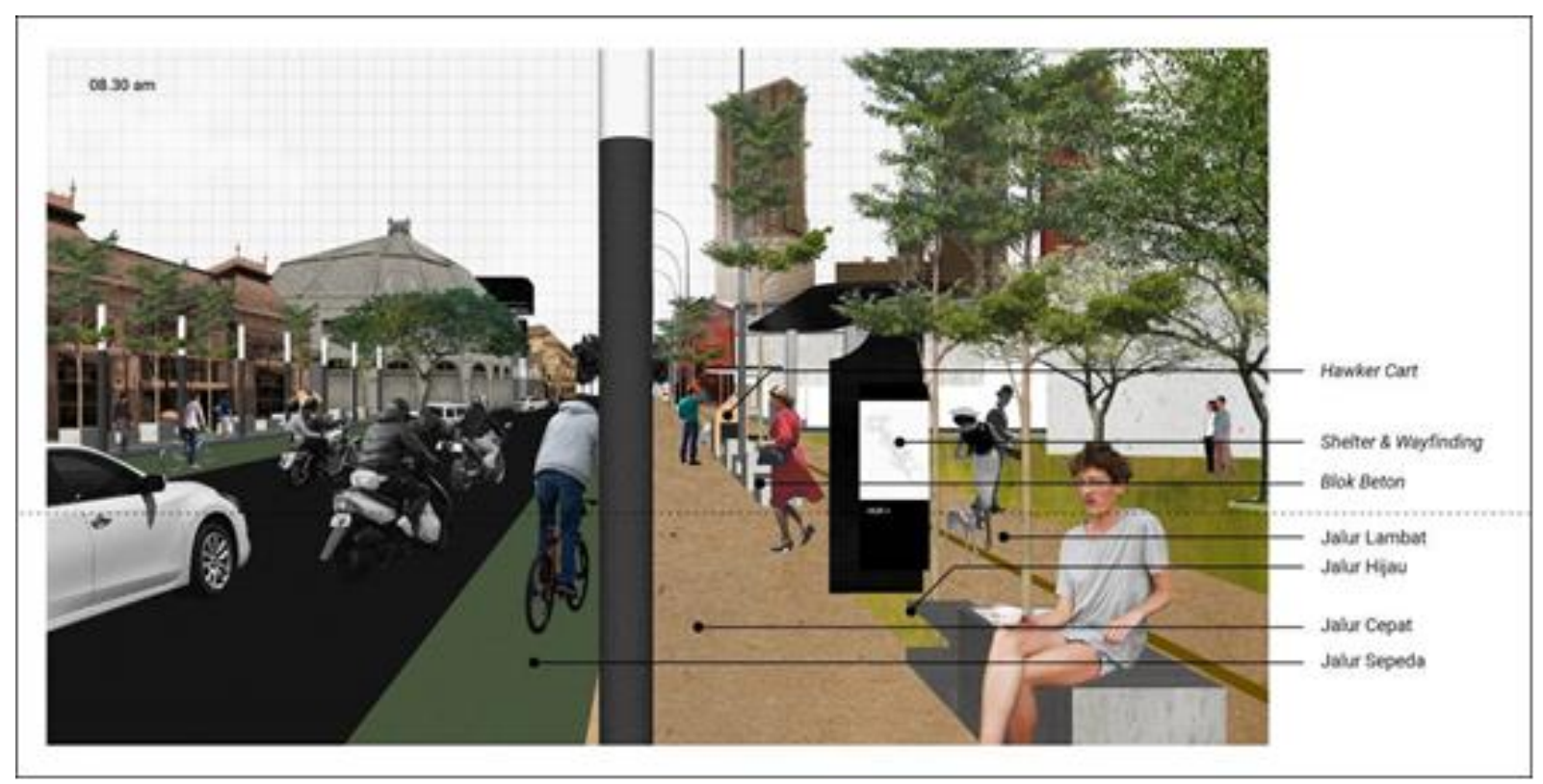

Gambar 14. Ilustrasi jalur pedestrian.

Untuk merespon variabel-variabel tersebut, maka jalur pedestrian akan dibagi menjadi empat zona dan jalur, yakni jalur lambat, jalur hijau, jalur cepat, dan jalur sepeda. Jalur lambat akan diprediksi menciptakan aktivitas dan kegiatan kreatif yang tidak terduga dalam proses perencanaan dan perancangan [27]. Jalur hijau sebagai area vegetasi untuk meningkatkan kualitas kenyamanan dan reduksi termal pada pedestrian. Jalur cepat akan diprediksi sebagai area sirkulasi yang direncanakan semi-steril terhadap aktivitas kreatif sehingga tidak menganggu pergerakan pedestrian. Serta, jalur sepeda sebagai area transportasi yang lebih mengedepankan akses transportasi yang lebih ramah lingkungan.

Saat melakukan perpindahan dari satu titik program ke program yang lain, dibutuhkan pergerakan melintasi lajur koridor utama Tunjungan sehingga perlu adanya fasilitas penyebrangan yang memadai untuk memudahkan konektivitas pengguna berupa zebra cross yang dilengkapi dengan lampu lalu-lintas. Fasilitas ini telah ada pada kawasan dan membantu mengurangi bahaya yang terjadi akibat kelalaian maupun ketidaksengajaan yang ditimbulkan oleh transportasi yang melintasi koridor Tunjungan. Skenario pergerakan pengguna akan diprediksi seperti yang diinformasikan pada Gambar 15. 


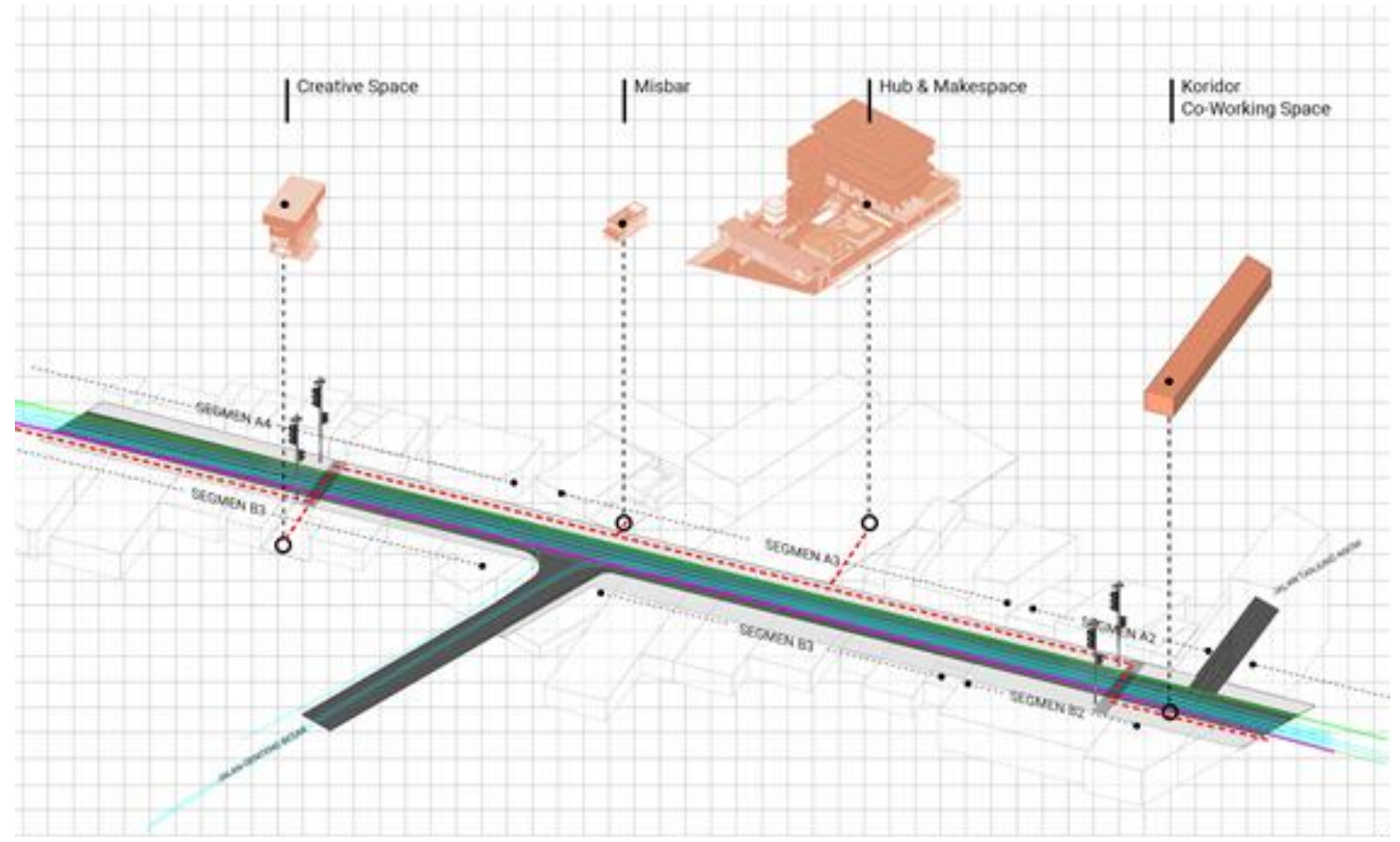

Gambar 15. Diagram pergerakan pengguna.

Garis warna merah menunjukkan skema pergerakan melalui jalur pedestrian dari satu program ke program yang lain (co-working space - maker space - creative space) sebagai implementasi dari alur kegiatan kreatif, yakni input - proses - output. Garis warna ungu, biru, dan hijau menunjukkan pergerakan transportasi yang melintasi koridor Tunjungan. Sehingga, proses pergerakan yang telah diatur ini dapat memberikan kenyamanan kepada pengguna saat melakukan perpindahan antar program sekaligus mempengarui area-area pada kawasan yang terdisrupsi oleh pergerakan pengguna untuk tumbuh dan berkembang menjadi kawasan yang lebih hidup.

Selain itu, akan ditambahkan street furniture yang akan menunjang kenyamanan pergerakan pengguna. Street furniture atau street amenities ini terdiri atas, hawker cart yang berfungsi sebagai slot PKL, shelter dan wayfinding yang berfungsi sebagai papan informasi terkait dengan kondisi kawasan, serta blok-blok beton yang menjadi variasi green area sekaligus sebagai tempat duduk bagi pengguna. Street furniture ini akan berperan untuk merejuvenasi dan menambah kualitas kenyamanan jalur pedestrian. Beberapa contoh dari street furniture dapat dilihat pada Gambar 16. 


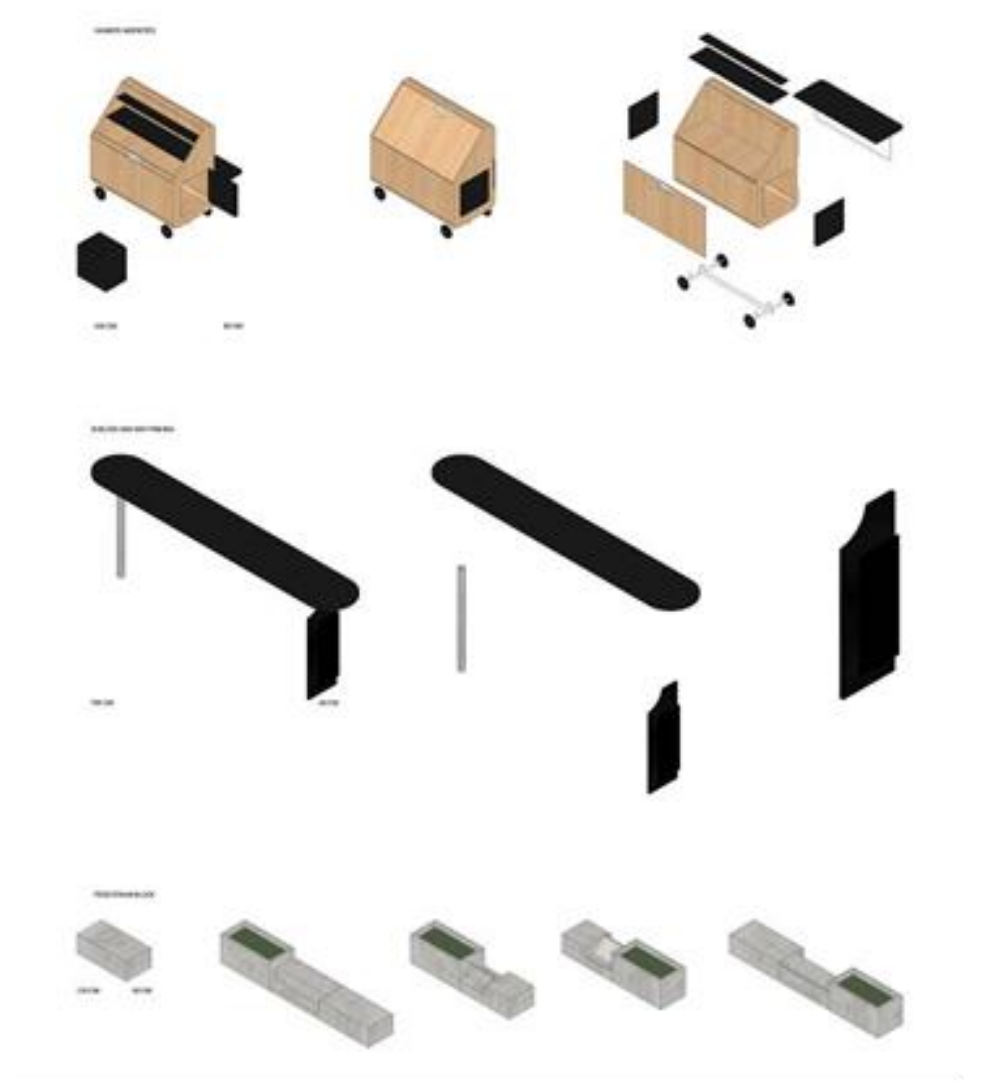

Gambar 16. Street furniture.

\section{Kesimpulan}

Hasil dari studi ini adalah pemahaman mengenai status identitas Kawasan Historis Tunjungan yang dinamis sebagai artefak urban yang menjadi bagian dari fragmen kota. Tunjungan yang saat ini telah diprediksi menjadi lost space akan diakuisisi kembali dengan fungsi baru melalui kegiatan kreatif untuk menciptakan identitas yang baru sebagai distrik kreatif. Identitasnya sebagai distrik kreatif akan diwujudkan melalui creative hub sebagai program arsitektur yang diinjeksikan pada konteks kawasan saat ini dan berperan sebagai katalis untuk mendorong kembalinya Tunjungan yang dapat menjadi penanda aktivitas masyarakat Kota Surabaya.

Proses yang dilakukan untuk mengaktivasi Kawasan Historis Tunjungan ialah dengan merencanakan penempatan program dari sebuah creative hub dan bagaimana programprogram ini dapat diintegrasikan dengan Tunjungan. Selain itu, program-program sebuah creative hub akan dirancang untuk mengaktivasi proses kreatif pada setiap pengguna dengan menggunakan aplikasi ruang kreatif dan parameter pendukung lainnya.

Studi ini perlu dikembangkan lebih lanjut mengenai integrasi visual - yang berperan sebagai faktor integrasi non fisik - antara program kreatif yang akan diinjeksikan dengan konteks Kawasan Tunjungan. Meskipun program-program injeksi dapat memiliki karakternya sendiri, namun eksistensinya sebagai katalis perkembangan kawasan tetap dapat dimaknai sebagai bagian dari identitas Tunjungan. Sehingga, tujuan untuk menjadikan Kawasan Historis 
Tunjungan sebagai distrik kreatif yang juga sebagai museum perkembangan kota dapat dicapai dengan maksimal.

\section{Referensi}

[1] Samidi. Surabaya sebagai Kota Kolonial Modern pada Akhir Abad ke-19: Industri, Transportasi, Permukiman, dan Kemajemukan Masyarakat. Mozaik Hum 2017;17:157-80. https://doi.org/10.20473/mozaik.v17i1.6597.

[2] Handinoto. Perkembangan Kota dan Arsitektur Kolonial Belanda di Surabaya, 18701940. Surabaya: Universitas Kristen Petra Surabaya; 1996.

[3] Dick HW. Surabaya, City of Work: A Socioeconomic History, 1900-2000. Athens: Ohio University Press; 2002.

[4] Poerbantanoe B. The Lost City dan Lost Space Karena Perkembangan Tata Ruang Kota: Kasus Koridor Komersial Jalan Tunjungan Kotamadya Surabaya. Dimens Tek Arsit 1999;27:31-9. https://doi.org/10.9744/dimensi.27.2.

[5] Kusumo C. Railway Station, Centres and Markets: Change and Stability in Patterns of Urban Centrality. Technische Universiteit Delft, 2007.

[6] Muftianti RD. Mengembalikan Spirit of Place, Sebuah Upaya Mempertahankan Citra Koridor Jalan Tunjungan Surabaya. E-Jurnal Eco-Teknologi UWIKA 2013;1:23-32.

[7] Trancik R. Finding Lost Space: Theories of Urban Design. New York: Van Nostrand Reinhold Company; 1986.

[8] Howkins J. The Creative Economy: How People Make Money from Ideas. London: Penguin Press; 2001.

[9] Siregar F, Sudrajat D. Enabling Spaces: Mapping Creative Hubs In Indonesia. Jakarta: Centre for Innovation Policy and Governance Indonesia Sustainability Centre; 2007.

[10] Virani T. Re-articulating the creative hub concept as a model for business support in the local creative economy : the case of Mare Street in Hackney. Creat London Work Pap Ser Number 12 2015:1-27.

[11] Plowright PD. Revealing Architectural Design: Methods, Frameworks and Tools. 1st ed. New York: Routledge; 2014. https://doi.org/10.4324/9781315852454.

[12] Krathwohl DR. A Revision of Bloom's Taxonomy: An Overview. Theory Pract 2002;41.

[13] Danisworo M, Martokusumo W. Revitalisasi Kawasan Kota, Sebuah Catatan dalam Pengembangan dan Pemanfaatan Kawasan Kota. Newsl URDI (Urband Reg Dev Institute) 2002;13.

[14] Vygotsky LS. Play and Its Role in the Mental Development of the Child. Vopr Psihol 1967;12:62-76. https://doi.org/10.2753/rpo1061-040505036.

[15] Thoring K, Luippold C, Mueller RM. Creative Space in Design Education: A Typology of Spatial Functions. 14th Int. Conf. Eng. Prod. Des. Educ. Des. Educ. Futur. Wellbeing, EPDE 2012, Antwerp: Artesis University College; 2012, p. 475-80.

[16] Mark DM. Human Spatial Cognition. London: Belhaven Press; 1993.

[17] Pallasmaa J. The Eyes of the Skin: Architecture and the Senses. 2nd ed. Chichester: Wiley Academy; 2005.

[18] Smith JD, Berg ME, Cook RG, Murphy MS, Crossley MJ, Boomer J, et al. Implicit And Explicit Categorization: A Tale of Four Species. Neurosci Biobehav 2012;36. 
https://doi.org/10.1016/j.neubiorev.2012.09.003.

[19] Gourlay S. Tacit Knowledge - A New Hypothesis. Edinburgh: 2000.

[20] Bloom BS, Engelhart MD, Furst EJ, Hill WH, Krathwohl DR. Taxonomy of educational objectives: The Classification of Educational Goals. New York: Longmans; 1956.

[21] Kauffman JC, Beghetto R. Beyond Big and Little: The Four C Model of Creativity. Rev Gen Psychol 2009;13:1-12.

[22] Holman W. Makerspace: Towards a New Civic Infrastructure. Places 2015. https://doi.org/10.22269/151130.

[23] Al-Yousif IJ, Hussein MM. Urban Integration of Historic Centers: Analytical Study of the Factors of Urban Integration at Al-Karkh Historic Center. Iraqi J Archit Plan 2013;12:127.

[24] Hillier B, Hanson J. The Social Logic of Space. Cambridge: Cambridge University Press; 1984. https://doi.org/10.1017/CBO9780511597237.

[25] Krisetya AT, Navastara AM. Identifikasi Karakteristik Fisik Koridor Jalan Tunjungan sebagai Ruang Publik. J Tek ITS 2018;7:162-7. https://doi.org/10.12962/j23373539.v7i2.32695.

[26] Appleyard M, Genson S, Lintell M. Livable Streets. Berkeley: University of California Press; 1981.

[27] Oswalt P, Misselwitzz P, Overmeyer K. Patterns of the Unplanned: Urban Catalyst. Loose Sp. Possibility Divers. Urban Life. 1st ed., London: Routledge; 2006. https://doi.org/10.4324/9780203799574. 